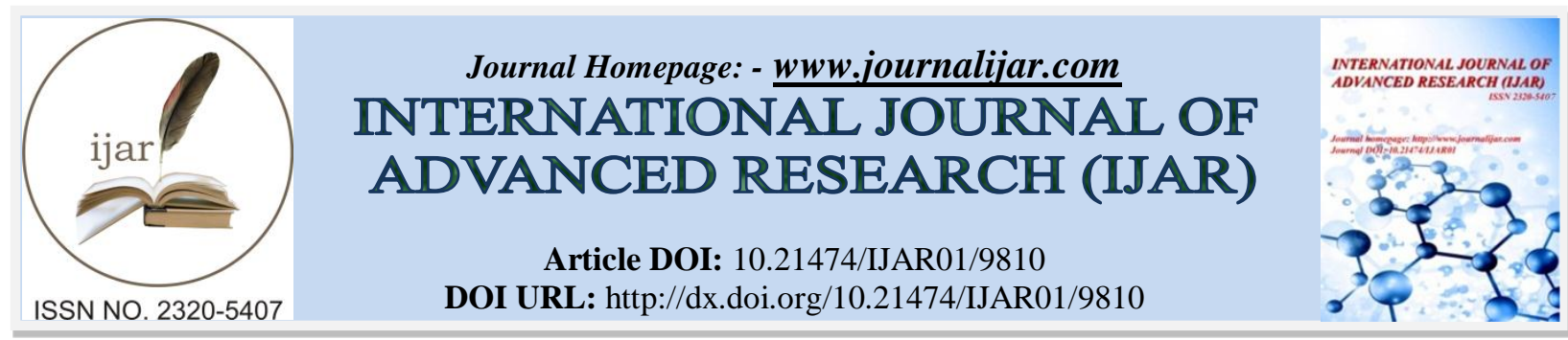

RESEARCH ARTICLE

\title{
LARVICIDAL EFFICACY OF FRACTIONATED ESSENTIAL OILS OF TAGETES MINUTA, OCIMUM KILIMANDSCHARICUM, AND ARTEMISIA AFRA AGAINST ANOPHELES GAMBIAE S.S.
}

Christopher Ong'au Misire ${ }^{1}$, Moses Mwajar Ngeiywa ${ }^{2}$ and Frederick Muyoma Wanjala ${ }^{3}$.

1. Department of Biological Sciences, University of Kabianga, P.O. Box 2030-20200, Kericho.

2. Department of Biological Sciences, University of Eldoret, P.O. Box 1125-30100, Eldoret.

\section{Manuscript Info}

Manuscript History

Received: 04 August 2019

Final Accepted: 06 September 2019

Published: October 2019

Key words:-

Human malaria, Anopheles gambiae s.s., Larval control, Essential oil fractions.

\begin{abstract}
The growing concern over environmental ills caused by synthetic insecticides employed to control malaria vectors has renewed interest in the search for ecofriendly alternatives. This study evaluated the larvicidal efficacy of fractions obtained from essential oils (EOs) of Tagetes minuta, Ocimum kilimandscharicum and Artemisia afra against Anopheles gambiae s.s. A total of 23, 14 and 7 fractions were isolated from EOs of $T$. minuta (coded 1 to 23), O. kilimandscharicum (coded A to $\mathrm{N}$ ) and $A$. afra (coded X-1 to X-7), respectively. Preliminary tests were done to eliminate fractions with less potent compounds from which one fraction (2), two fractions (A and F), and two fractions (X-1 and X-2) were selected for subsequent bioassays. Chemical analysis of the five fractions with potent compounds was done using Gas Chromatography-Mass Spectrometry (GC-MS) with the major constituents being $\beta$-ocimene $(56.29 \%)$ in fraction $2, \alpha$-cubebene $(29.39 \%)$ in fraction A, $\beta$-caryophyllene (31.48\%) in fraction F, and $\beta$ thujone $(37.41 \%)$ in fraction $\mathrm{X}-1$, and ethyl-2-octynoate $(40.80 \%)$ in fraction X-2, respectively. Data obtained were subjected to probit analysis using STATISCA 6.0 statistical software to model the relationship between the response variables and factors. Fraction $\mathrm{F}$ was the most efficacious under laboratory conditions, followed by X-1, A, $\mathrm{X}-2$, and 2, respectively. A similar trend of larval mortalities was observed under simulated field conditions (SFC) with significantly higher $(P \leq 0.05)$ mortalities recorded under SFC than under laboratory conditions. The outcome in all the tests performed were both dose and time depended. Two fractions, Fraction F- a slightly polar eluate from $O$. kilimandscharicum, and Fraction X-1- a nonpolar eluate from A. afra, exhibited high potency and should be explored further with the aim of formulating commercially viable larvicides.
\end{abstract}

Copy Right, IJAR, 2019. All rights reserved.

\section{Introduction:-}

Malaria is a major global public health problem and a leading cause of morbidity and mortality in many countries (WHO, 2013). Many approaches have been developed to control the mosquito vectors (Sanei-Dehkordi, et al., 2016) but despite intensive efforts, the disease incidence continues to proliferate and cause enormous mortality and 
debilitation rates (Cuthbert, et al., 2019) with huge economic losses (Afolabi, et al., 2018) in the resource-limited settings of Africa, Asia, Latin America, and beyond (Karunamoorthi, et al., 2014). Chemical control using long lasting insecticide treated nets (LLINs) remains the most effective tool for intervention, with pyrethroids being the only class, out of the four conventional insecticides, recommended for use in LLINs by WHO (Kisinza, et al., 2017; WHO, 2018; Zoh, et al., 2018).

The ever-changing climatic conditions and complex social structures (Cuthbert, et al., 2019), and the development of multiple resistances by mosquito vector species to synthetic insecticides of different classes currently in use (Uragaya, et al., 2015; WHO, 2018), pose a bigger challenge in combating the disease (Pavela, et al., 2019). Prevention and control efforts of human malaria, according to WHO (2018), are threatened by the resistance of the malaria vectors to pyrethroids that are used in all insecticide treated mosquito nets (ITNs), and to the four insecticide classes used for indoor residual spraying (IRS).

Anopheles gambiae s.s., the major Afrotropical malaria vector, is predominantly associated with the most virulent malaria parasite, Plasmodium falciparum (Zoh, et al., 2018), whose multi-drug resistance to artemisinin combined therapy (ACT), the current drugs of choice, has been reported from many parts of the world (WHO, 2018; Hamilton, et al., 2019). Camara, et al. (2018), reported that An. gambiae mosquitoes had developed widespread and strong resistance to organochlorines and pyrethroids, and moderate level resistance to organophosphates. Lynd, et al. (2018), and Okia et al. (2018), detected a high frequency of phenotypic resistance to two pyrethroids, deltamethrin and permethrin, and an organochlorine, dichlorodiphenyltrichroethane (DDT) in An. gambiae s.s. This rapid evolution of insecticide resistance phenotypes was attributed to a selective pressure with multiple origins, the most significant being exposure to synthetic insecticides used in vector control (Camara, et al., 2018), which according to Lynd et al. (2018), and Okia et al. (2018), provides an enormous challenge for LLIN-based vector control programmes.

It has also been reported that during the period 2010-2017, insecticide resistance existed in 68 of the 80 endemic countries to at least one insecticide in one malaria vector from one collection site, with three countries reporting resistance for the first time, and the detected resistance to each class being; $82 \%$ for organochlorines, $82 \%$ for pyrethroids, 63\% for carbamates, and 50\% for organophosphates (WHO, 2018). According to Uragaya et al (2015), there are limited options for management of insecticide resistance prompted by conventional insecticides, necessitating the search for ecofriendly alternatives for effective control of the malaria vectors.

Phytochemicals and their derivatives have been considered potential suitable replacements to synthetic insecticides (Sanei-Dehkordi, et al., 2016), with major research efforts directed towards investigating their insecticidal activity against various developmental stages of the mosquito vectors in a bid to reduce the frequent over reliance on conventional insecticides (Pavela, et al., 2019). Elsewhere, products from Tagetes minuta (Asteraceae), Ocimum kilimandscharicum (Lamiaceae) and Artemisia afra (Asteraceae) have yielded promising efficacy against a number of organisms including the malaria vectors when used alone (Bekele, 2018). The current study sought to evaluate the efficacy of fractions isolated from essential oils (EOs) of T. minuta, O. kilimandscharicum and A. afra, against third instar larvae of An. gambiae s.s. under laboratory and simulated field conditions.

\section{Methodology:-}

The study was carried out at the Centre for Global Health Research (CGHR) CDC-KEMRI located about $10 \mathrm{Km}$ from Kisumu City along the Kisumu-Busia road. The station lies on the coordinates $0^{\circ} 4^{\prime} 40^{\prime \prime} \mathrm{N} \quad 34^{\circ} 40^{\prime} 38^{\prime \prime E}$. Kisumu City, in western Kenya, is an area endemic for major infectious diseases including malaria.

\section{Research Design}

This study employed an experimental research design and followed the post-test only assessment. Two groups were randomly selected, the experimental and control groups, with the latter comprising of positive and negative controls. The positive controls contained the recommended $1 \mathrm{~g} / \mathrm{L}$ of Bi-Larv ${ }^{\mathrm{TM}} 25 \mathrm{WP}$ (a registered trademark product of Bayer Pharmaceutics Company in wettable powder containing 25\% diflubenzuron, an insect growth regulator (IGR) as the active ingredient, and is listed under WHO Pre-Qualification (WHO-PQ) scheme) while the negative controls contained $1 \mathrm{~mL}$ acetone in $250 \mathrm{~mL}$ solution. 


\section{Harvesting and Identification}

Fresh full-bloom aerial parts of T. minuta, O. kilimandscharicum, and A. afra, were collected from the confines of the University of Eldoret (UoE) located $11 \mathrm{~km}$ North of Eldoret town in Uasin Gishu County, Kenya. The town is about $320 \mathrm{~km}$ Northwest of Nairobi and lies between $0^{\circ} 15.5^{\prime} \mathrm{N}$ and $0^{\circ} 20^{\prime} \mathrm{N}$ latitudes, and on longitude $35^{\circ} 19^{\prime} \mathrm{E}$. The altitude of the area is 2080 metres above sea level. Samples of the plant materials were deposited at the UoE's herbarium for identification. The three plants were identified as Tagetes minuta, voucher number (VN): MU/0003/87, Ocimum kilimandscharicum, VN: MU/0033/89, and Artemisia afra, VN: MU/0107/87. The freshly collected plant materials were taken to the laboratory for processing.

\section{Extraction of Essential Oils}

The plant materials were chopped into small pieces and stuffed into a round-bottomed flask. EOs of each plant species were extracted separately by steam distillation following the methods described by (Pavia, et al., 1982; Baser and Buchbauer, 2010). For each plant species, 500 grams of chopped fresh plant material was stuffed separately into a $1000 \mathrm{~mL}$ conical flask which was tightly corked with a two-delivery tubes fitted cork, one connected to $1000 \mathrm{~mL}$ round bottomed flask containing boiling water (source of steam), and the other connected to a din and stack connected to a Liebig condenser. Steam from the boiling water in the round bottomed flask, heated using a Bunsen burner, was passed through the plant material in order to vaporize the EOs. During the distillation process, a continuous stream of cold water was run through the condenser to liquefy the vaporized EOs. The EOs obtained were dried using anhydrous calcium chloride and stored in tightly corked glass vials at $4^{0} \mathrm{C}$ awaiting further use.

\section{Fractionation of Essential Oils by Column Chromatography}

$50 \mathrm{~g}$ of EOs of $T$. minuta, O. kilimandscharicum, and A. afra were separately weighed accurately using an analytical balance of $0.001 \mathrm{~g}$ sensitivity then each was mixed with $50 \mathrm{~g}$ accurately weighed silica gel. The mixtures were thoroughly stirred using pestle and mortar and the resulting homogeneous pastes left to stand for 48 hours in a dry place at room temperature and pressure (rtp) for them to dry.

Each of the dry mixtures was packed in a column using slurry method as described by Pavia et al, (1982) and Baser and Buchbauer, (2010), with hexane as the eluent. The sample mixtures were carefully added separately to the column then a piece of cotton wool was placed on top of the sample to prevent disturbance of the sample layer during addition of the eluent and to obtain horizontal bands during elution. The polarity of the moving phase (eluent) was increased from non-polar (100\% hexane: $0 \%$ ethyl acetate) to polar ( $0 \%$ hexane: $100 \%$ ethyl acetate) by increasing the polarity at $5 \%$ intervals while collecting the eluates in clean dry test tubes. Polarity was further increased using methanol at the same intervals from $100 \%$ ethyl acetate to $100 \%$ methanol (high polar) with the last concentration added twice to elute high polar compounds.

The compounds in the different eluates were determined using thin layer chromatography (TLC) by carefully spotting them on TLC plates as described by Baser and Buchbauer, (2010). The TLC plates were then immersed in developing solvent mixtures containing ethyl acetate and hexane, at different ratios (2:8, 3:7, and 4:6, respectively) containing two drops of acetic acid to prevent tailing. The TLC plates were removed from the developing solvent when the solvent fronts had moved about $3 / 4$ of the distance, and the solvent front marked immediately (Pavia et al, 1982). The TLC plates were then immersed in a visualizer, containing 5\% sulphuric acid in methanol for 30 seconds, then left to dry before viewing the compounds using an ultra violet (UV) lamp (Pavia et al, 1982). The locations of the compounds were marked using a pencil for calculation of retention factor $\left(R_{f}\right)$ values.

The fractions obtained at different polarities were coded differently for each plant with those obtained from $T$. minuta laboratory coded 1 to 23 , with 1 comprising of non-polar eluates while 23 comprised of high polar eluates. Fractions obtained from $O$. kilimandscharicum were coded A to $\mathrm{N}$, with A comprising of non-polar eluates while $\mathrm{N}$ comprised of high polar eluates. Fractions obtained from A. afra were coded X-1 to X-7, with the former comprising of non-polar eluates and the latter comprising of high polar eluates. The contents of test tubes with similar $R_{f}$ values were mixed together and then concentrated by vacuum distillation using a Rotavapor at $40^{\circ} \mathrm{C}$.

Laboratory Rearing of Anopheles gambiae s.s.

100 three-day old females of An. gambiae s.s. Kisumu strain were obtained from the insectary at the CGHR CDCKEMRI, Kisumu and provided with a blood meal from a laboratory rabbit that was sheared on the back. Twenty fully engorged blood fed females were put into rearing cages measuring $30 \mathrm{~cm}$ x $30 \mathrm{~cm}$ x $30 \mathrm{~cm} .30 \mathrm{~mL}$ plastic cups 
containing oviposition substrate were provided in the cages. Laid eggs were transferred to $500 \mathrm{~mL}$ white plastic trays half-filled with dechlorinated water. Freshly hatched larvae were fed on a sprinkle of larval food comprising of a mixture of ground dog biscuits and brewer's yeast, and the ration was gradually increased as larvae increased in size. The rearing water was replenished after every 48 hours to prevent fouling and larval mortalities. Up to 100 pupae were transferred to $100 \mathrm{~mL}$ plastic cups containing rearing water and put into the rearing cages for adult emergence.

For colony maintenance, adult males and females were kept together and provided with ad libitum $10 \%$ sucrose solution, while females were provided with blood meal from a sheared rabbit following the method used by Amerasan, et al., (2012). The larvae used in both laboratory and SFC experiments were obtained from the reared colony, which was maintained at a temperature of $27 \pm 2^{\circ} \mathrm{C}$, relative humidity $(\mathrm{RH})$ of $75 \pm 5 \%$, and a 12L:12D (Light: Dark) photoperiod.

\section{Bioassays under Laboratory Conditions}

$1 \%$ stock solutions of all the 44 fractions obtained from column chromatography were prepared from which serial dilutions were done following WHO (2005) protocol. $200 \mathrm{ppm}$ test solutions of each fraction were prepared in 250 $\mathrm{mL}$ volumes contained in $500 \mathrm{~mL}$ white plastic trays, unto which thirty third instar larvae of An. gambiae s.s. were exposed for 48 hours to eliminate those with less potent compounds. Each setup comprised of triplicate sets of the same fraction and the tests were repeated three times. Larval food was added to each test solution every morning. Fractions, whose solutions caused at least 10\% larval mortality within 48 hours, were selected and used in subsequent bioassays.

Fraction 2, obtained from non-polar eluates (100 - 90\% n-hexane: 0 - 10\% ethyl acetate) of T. minuta, fractions A and $\mathrm{F}$ obtained from non-polar eluates (100 - 95\% n-hexane: 0 - 5\% ethyl acetate) and slightly polar eluates (90 85\% n-hexane: 10 - 15\% ethyl acetate) of $O$. kilimandscharicum, and fractions X-1 and X-2 obtained from non-polar eluates (100 - 95\% n-hexane: $0-5 \%$ ethyl acetate) slightly polar eluates (95-90\% n-hexane: $5-10 \%$ ethyl acetate) of A. afra, respectively, were selected. Eight different ppm concentrations of the five fractions, ranging from 25 to $200 \mathrm{ppm}$ at intervals of $25 \mathrm{ppm}$, were prepared and their efficacy tested against third instar larvae of An. gambiae s.s. alongside positive $\left(1 \mathrm{~g} / \mathrm{L} \mathrm{Bi}-\mathrm{Larv}^{\mathrm{TM}} 25 \mathrm{WP}\right)$ and negative $(1 \mathrm{~mL}$ acetone) controls in $250 \mathrm{~mL}$ solutions, under laboratory conditions. Thirty larvae were exposed to each treatment.

\section{Bioassays under Simulated Field Conditions}

Simulated field conditions (SFC) trials were done, following the WHO protocol on pesticide evaluation (WHO, 2005), using the fractions that had been selected under laboratory conditions. Sixty 5L basins were placed in rows that were one by one metre apart. The basins were smeared with clay soil on the inside to near brim and filled with $1000 \mathrm{~mL}$ of dechlorinated water, marked and left overnight. In the day that followed, dechlorinated water was filled to mark and left to settle before a batch of 50 laboratory-reared early third instar larvae of An. gambiae s.s. was released into each container and a sprinkle of larval food added. After 3 hours of larval acclimation, the set-ups were treated with different doses of the selected fractions in a completely randomized manner using micro-pipettes.

The containers were covered with a mosquito netting material to prevent other mosquitoes and/or insects from laying eggs and to protect the water from falling debris. Live larvae were counted after every 24 hours to score posttreatment larval mortality. The water level in the containers was maintained to mark for 72 hours. The remaining larvae and/or pupae were destroyed after 72 hours and the smeared mud discarded and replaced with fresh mud before the next trial. The test trials were repeated five times. The positive control contained the recommended $1 \mathrm{~g} / \mathrm{L}$ concentration of Bi-Larv ${ }^{\mathrm{TM}} 25 \mathrm{WP}$ while the negative control contained $4 \mathrm{~mL}$ of acetone in $1000 \mathrm{~mL}$ solution.

\section{Chemical Analysis of Fractions with Potent Compounds Sample Preparation}

A stock solution of $1 \mathrm{mg} / \mathrm{ml}$ of each sample was prepared and to it $1 \mu \mathrm{l}(100 \mathrm{pg} / \mu \mathrm{l})$ of internal standard, 1-heptene was added followed by $50 \mathrm{mg}$ of $\mathrm{Na}_{2} \mathrm{SO}_{4}$ (drying agent). The samples were vortexed for $1 \mathrm{~min}$, extracted by ultrasonication in sonication bath (Branson 2510, Danbury, CT, USA) for $10 \mathrm{~min}$, centrifuged at 13,000 rpm for 5 $\min$ at $5^{\circ} \mathrm{C}$ and the supernatant filtered by passing through glass wool each before analysis by GC-MS. The analysis was replicated 3 -times. 


\section{Gas Chromatography Coupled Mass Spectrometry (GC-MS) Analysis}

GC-MS in full scan mode was used to detect and profile all the compounds present in the extracts. The extracts were analyzed by GC-MS on a 7890A gas chromatograph (Agilent Technologies, Inc., Santa Clara, CA, USA) linked to a 5975 C mass selective detector (Agilent Technologies, Inc., Santa Clara, CA, USA) by using the following conditions: inlet temperature $270^{\circ} \mathrm{C}$, transfer line temperature of $280^{\circ} \mathrm{C}$, and column oven temperature programmed from $40^{\circ} \mathrm{C}$ to $285^{\circ} \mathrm{C}$ with the initial temperature maintained for $5 \mathrm{~min}$ then $10^{\circ} \mathrm{C} / \mathrm{min}$ to $280^{\circ} \mathrm{C}$ held at this temperature for $10.5 \mathrm{~min}$ and finally $50^{\circ} \mathrm{C} / \mathrm{min}$ to $285^{\circ} \mathrm{C}$ and held at this temperature for $31.9 \mathrm{~min}$. The GC was fitted with a HP-5 MS low bleed capillary column $(30 \mathrm{~m} \times 0.25 \mathrm{~mm}$ i.d., $0.25 \mu \mathrm{m})(\mathrm{J} \& \mathrm{~W}$, Folsom, CA, USA). Helium at a flow rate of $1.25 \mathrm{ml} / \mathrm{min}$ served as the carrier gas. The mass selective detector was maintained at ion source temperature of $230^{\circ} \mathrm{C}$ and a quadruple temperature of $180^{\circ} \mathrm{C}$. Electron impact (EI) mass spectra were obtained at the acceleration energy of $70 \mathrm{eV}$. A $1.0 \mu \mathrm{l}$ aliquot of extract was injected in the split/ splitless mode using an auto sampler 7683 (Agilent Technologies, Inc., Beijing, China). Fragment ions were analyzed over 40-550 $\mathrm{m} / \mathrm{z}$ mass range in the full scan mode. The filament delay time was set at $5 \mathrm{~min}$.

The compounds were identified by comparison of gas chromatographic retention time and fragmentation pattern with that of the authentic standards. When there was lack of corresponding reference compounds, the structures were proposed on the basis of their general fragmentation and using reference spectra published by library-MS databases: National Institute of Standards and Technology (NIST). The peak area of the internal standard, 1-heptene was used for quantification.

\section{Data analysis:}

The bioassays performed against An. gambiae s.s. during this study consisted of mortality and survival, all considered as response variables against varying concentrations of the fractions. The response variables were binary in nature (died/survived) and naturally followed a binomial distribution (Agresti, 1990). Therefore, the relationship between the response variables and factors were modeled using Probit analysis using STASTICA 6.0 statistical software. Maximum likelihood was used to estimate the regression coefficient ( $\mathrm{R}$ square) because it gives more precise estimation of necessary parameters for correct evaluation of the results (Finney, 1952). During Probit analysis, all data were transformed to $\log _{10}$ to linearize the relationship between the response variables and factors. The response frequency was observed as response variables from a total observation of 30 larvae of An. gambiae s.s., while the concentrations of the fractions were covariate.

The resulting probability outcomes were multiplied by 100 to determine the expected percentage of the response frequency. To test for the significance of the Probit plots, $\mathrm{Z}$ statistics were calculated; the larger the $\mathrm{Z}$ statistics the larger the differences from the smaller sized $Z$. Nevertheless, the differences were verified using P-value of $\leq 0.05$. The modeled fit was confirmed using chi-square goodness of fit test between the observed response values and predicted probability of response values. The resultant graph plotted consisted of Probits of response variables in Yaxis and $\log _{10}$ concentration in $\mathrm{X}$-axis.

The $\mathrm{LC}_{50}$ and $\mathrm{LC}_{90}$ were determined by projecting the $\mathrm{Y}$ axis for a probit of 5.00 and 9.00 and taking the inverse $\log _{10}(\mathrm{X})$ of the concentration of the fractions. The $\mathrm{LC}_{50}$ and $\mathrm{LC}_{90}$ were then compared using One Way Analysis of variance (One-Way ANOVA) to test the efficacy of different fractions. Where significant differences existed following ANOVA, means were separated using Duncan's Multiple Range Test (DMRT). In all analyses, significant differences were declared at $\mathrm{P} \leq 0.05$.

\section{Results:-}

Based on the laboratory bioassays using different fractions, it was observed that larval mortalities followed a doseresponse pattern, with lower mortality recorded at lower exposure doses and higher mortality at higher exposure doses (Figure 1). Among the five fractions tested, larvicidal efficacy was highest in treatment solutions containing Fraction $\mathrm{F}, \mathrm{LC}_{50} 58.75 \mathrm{ppm}$ and $37.40 \mathrm{ppm}$ while the least efficacy was observed in Fraction 2 with $\mathrm{LC}_{50} 81.50 \mathrm{ppm}$ and 66.25 ppm after 24- and 48- hours of exposure, respectively.

During the experiment it was established that the differences in the $\mathrm{LC}_{50}$ and $\mathrm{LC}_{90}$ values of the mosquito larvae subjected to the different fractions from T. minuta, O. kilimandscharicum, and A. afra were significant $(\mathrm{P} \leq 0.05)$. Fraction $\mathrm{F}$ had the lowest concentration required to kill $50 \%$ and $90 \%$ of the An. gambiae s.s. larvae, followed by fractions X-1, A, X-2 and 2, respectively. Fractions X-2 and 2 showed lower efficacy and were unable to kill up to 
$90 \%$ of the mosquito larvae after 24- and 48-hours of exposure in concentrations of up to 200 ppm (Table 1). There was a significant difference $(\mathrm{P} \leq 0.05)$ between the efficacy of fractions and the positive control. The trend in larvicidal activity observed when the various fractions 2, A, F, X-1 and X-2 were tested against An. gambiae s.s., larvae alongside positive control was: Positive control > Fraction F > Fraction X-1 > Fraction A $>$ Fraction X-2 > Fraction 2.

Table 1: $\mathrm{LC}_{50}$ and $\mathrm{LC}_{90}$ values of mortalities of $A n$. gambiae s.s. larvae caused by the fractions isolated from EOs of T. minuta, O. kilimandscharicum and A. afra after 24- and 48- hours exposure periods

\begin{tabular}{|l|l|l|l|l|}
\hline \multicolumn{2}{|l|}{} & Exposure time & $48 \mathrm{~h}$ \\
\hline & $24 \mathrm{~h}$ & $\mathrm{LC}_{90}$ & $\mathrm{LC}_{50}$ & LC $_{90}$ \\
\hline Treatments & $\mathrm{LC}_{50}$ & $\mathrm{Na}$ & $43.80^{\mathrm{c}}$ & $85.80^{\mathrm{c}}$ \\
\hline Fraction X-1 & $64.10^{\mathrm{c}}$ & $\mathrm{Na}$ & $54.90^{\mathrm{d}}$ & $\mathrm{Na}$ \\
\hline Fraction A & $68.20^{\mathrm{d}}$ & $91.80^{\mathrm{b}}$ & $37.40^{\mathrm{b}}$ & $75.80^{\mathrm{b}}$ \\
\hline Fraction F & $58.75^{\mathrm{b}}$ & $\mathrm{Na}$ & $60.80^{\mathrm{e}}$ & $\mathrm{Na}$ \\
\hline Fraction X-2 & $72.50^{\mathrm{e}}$ & $\mathrm{Na}$ & $66.25^{\mathrm{f}}$ & $\mathrm{Na}$ \\
\hline Fraction 2 & $81.50^{\mathrm{f}}$ & $84.20^{\mathrm{a}}$ & $31.50^{\mathrm{a}}$ & $69.40^{\mathrm{a}}$ \\
\hline Positive control & $53.75^{\mathrm{a}}$ & 886.0000 & 973.0800 & 5124.0000 \\
\hline F-value & 134.9730 & $<0.001$ & 0.0005 & $<0.001$ \\
\hline P-value & $<0.001$ & & \\
\hline
\end{tabular}

Values with different superscripts along the column are significantly different $(\mathrm{P} \leq 0.05)$. Na denotes not attained.

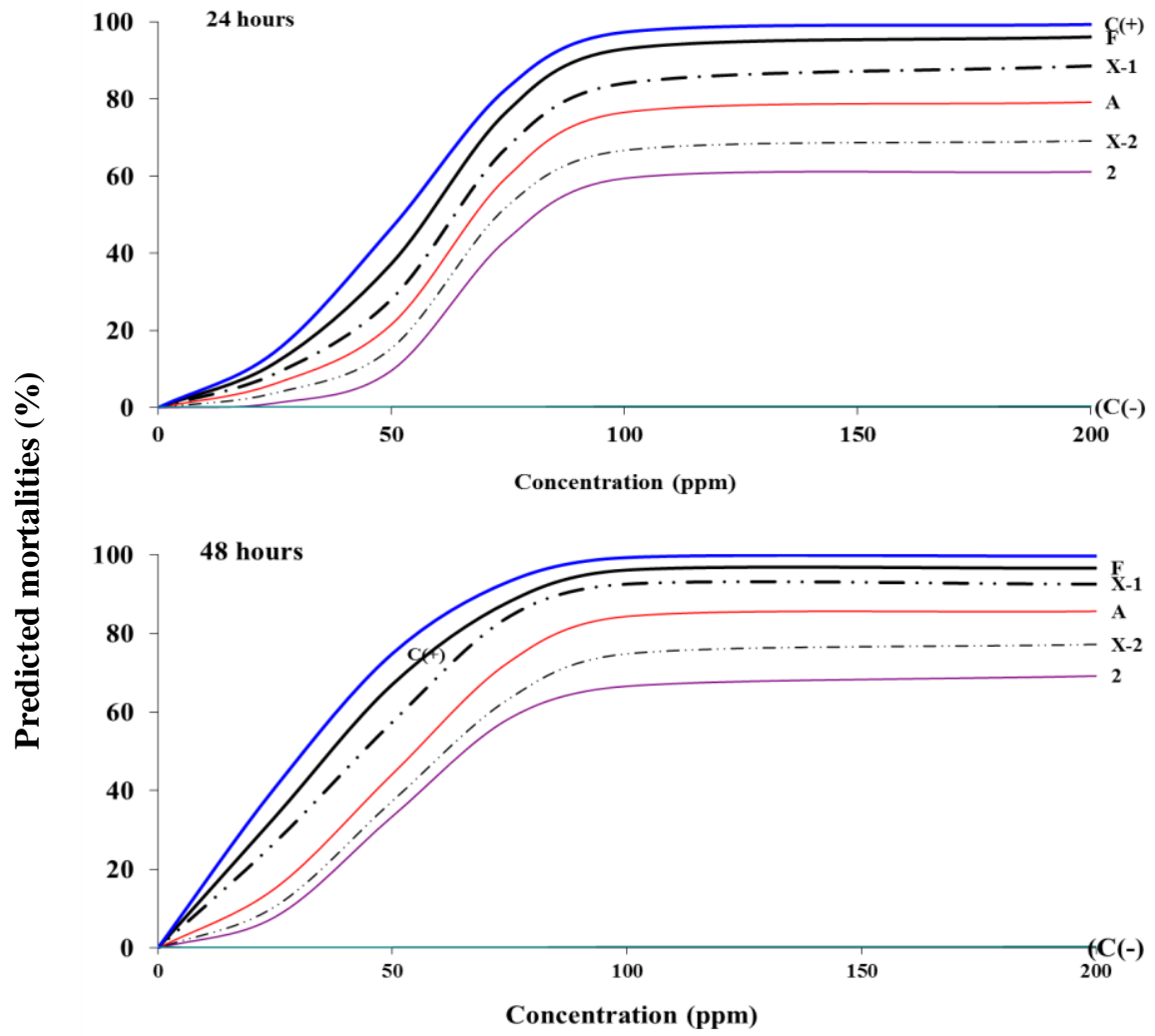

Figure 1: Mortalities of An. gambiae s.s. larvae caused by fractions isolated from EOs of T. minuta, O. kilimandscharicum, and A. afra after 24- hours and 48- hours of exposure.

Key:

$\mathrm{C}(+)$ - Positive Control (containing $1 \mathrm{~g} / \mathrm{L} \mathrm{Bi}-\mathrm{Larv}^{\mathrm{TM}} 25 \mathrm{WP}$ )

$\mathrm{C}(-)$ - Negative control (containing $4 \mathrm{~mL} / \mathrm{L}$ acetone)

$\mathrm{F}$ - Fraction F (containing 31.5\% $\beta$-Caryophyllene)

$\mathrm{X}$-1- Fraction X-1 (containing 37.4\% $\beta$-thujone) 
A - Fraction A (containing $29.3 \% \alpha$-Cubebene)

X- 2 - Fraction X-2 (containing $40.8 \%$ Ethyl-2-octynoate)

2 - Fraction 2 (containing $56.3 \%$-ocimene)

\section{Larvicidal activity of Fractions against An. gambiae s.s. Larvae under SFCs}

The mortality trends observed under SFC experiments were similar to those observed under laboratory conditions and exhibited dose- and time-dependent patterns (Figure 2). However, the mortality rates were significantly higher under SFCs compared to those observed under laboratory conditions. The most effective fraction, with the lowest concentration required to kill $50 \%$ and $90 \%$ of An. gambiae s.s. larvae was Fraction $\mathrm{F}$ with $\mathrm{LC}_{50}$ values of 40.00 ppm and $29.20 \mathrm{ppm}$, while the least effective treatment solution contained Fraction 2 which was unable to cause $50 \%$ mortality of An. gambiae s.s. larvae at concentrations of up to $200 \mathrm{ppm}$ after 24 and 48 hours of exposure, respectively.

There were significant differences $(\mathrm{P} \leq 0.05)$ in the $\mathrm{LC}_{50}$ and $\mathrm{LC}_{90}$ values obtained when An. gambiae s.s. larvae were subjected to different fractions from EOs of T. minuta, O. kilimandscharicum and A. afra, alongside positive and negative controls, under SFCs (Table 2). Of the fractions tested, Fraction $\mathrm{F}$ had the least concentration required to cause $50 \%$ and $90 \%$ mortalities of An. gambiae s.s. larvae, respectively. Only two fractions, Fraction F and Fraction X-1, were able to cause up to $90 \%$ larval mortalities after both 24- and 48- hours of exposure while fractions A, X-2, and 2 were unable to cause up to $90 \%$ mortalities in treatment solutions of up to $200 \mathrm{ppm}$ in both of the exposure durations.

The trend in larvicidal activity observed when the various fractions of EOs extracted from T. minuta, $O$. kilimandscharicum, and A. afra were tested against larvae of An. gambiae s.s., alongside the positive control was: Positive control > Fraction F > Fraction X-1 > Fraction A > Fraction X-2 > Fraction 2.

Table 2: $\mathrm{LC}_{50}$ and $\mathrm{LC}_{90}$ values of larval mortalities of An. gambiae s.s. caused by fractions isolated from EOs of $T$. minuta, O. kilimandscharicum and A. afra after 24- and 48- hours of exposure under SFCs.

\begin{tabular}{|l|l|l|l|l|}
\hline \multicolumn{5}{|l|}{ Exposure time } \\
\hline & $24 \mathrm{~h}$ & $48 \mathrm{~h}$ & \multicolumn{2}{l|}{} \\
\hline Treatment & $\mathrm{LC}_{50}$ & $\mathrm{LC}_{90}$ & $\mathrm{LC}_{50}$ & $\mathrm{LC}_{90}$ \\
\hline Fraction X-1 & $46.20^{\mathrm{c}}$ & $90.80^{\mathrm{c}}$ & $37.70^{\mathrm{c}}$ & $83.80^{\mathrm{c}}$ \\
\hline Fraction A & $68.20^{\mathrm{d}}$ & $\mathrm{Na}$ & $46.20^{\mathrm{d}}$ & $\mathrm{Na}$ \\
\hline Fraction F & $40.00^{\mathrm{b}}$ & $76.90^{\mathrm{b}}$ & $29.20^{\mathrm{b}}$ & $60.10^{\mathrm{b}}$ \\
\hline Fraction X-2 & $\mathrm{Na}$ & $\mathrm{Na}$ & $\mathrm{Na}$ & $\mathrm{Na}$ \\
\hline Fraction 2 & $\mathrm{Na}$ & $\mathrm{Na}$ & $\mathrm{Na}$ & $\mathrm{Na}$ \\
\hline Positive control & $35.40^{\mathrm{a}}$ & $69.30^{\mathrm{a}}$ & $21.50^{\mathrm{a}}$ & $50.80^{\mathrm{a}}$ \\
\hline F-value & 686.9039 & 269.6925 & 168.7421 & 400.5494 \\
\hline P-value & $<0.001$ & $<0.001$ & $<0.001$ & $<0.001$ \\
\hline
\end{tabular}

Values with different superscripts along the column are significantly different $(\mathrm{P} \leq 0.05)$. Na denotes not attained. 

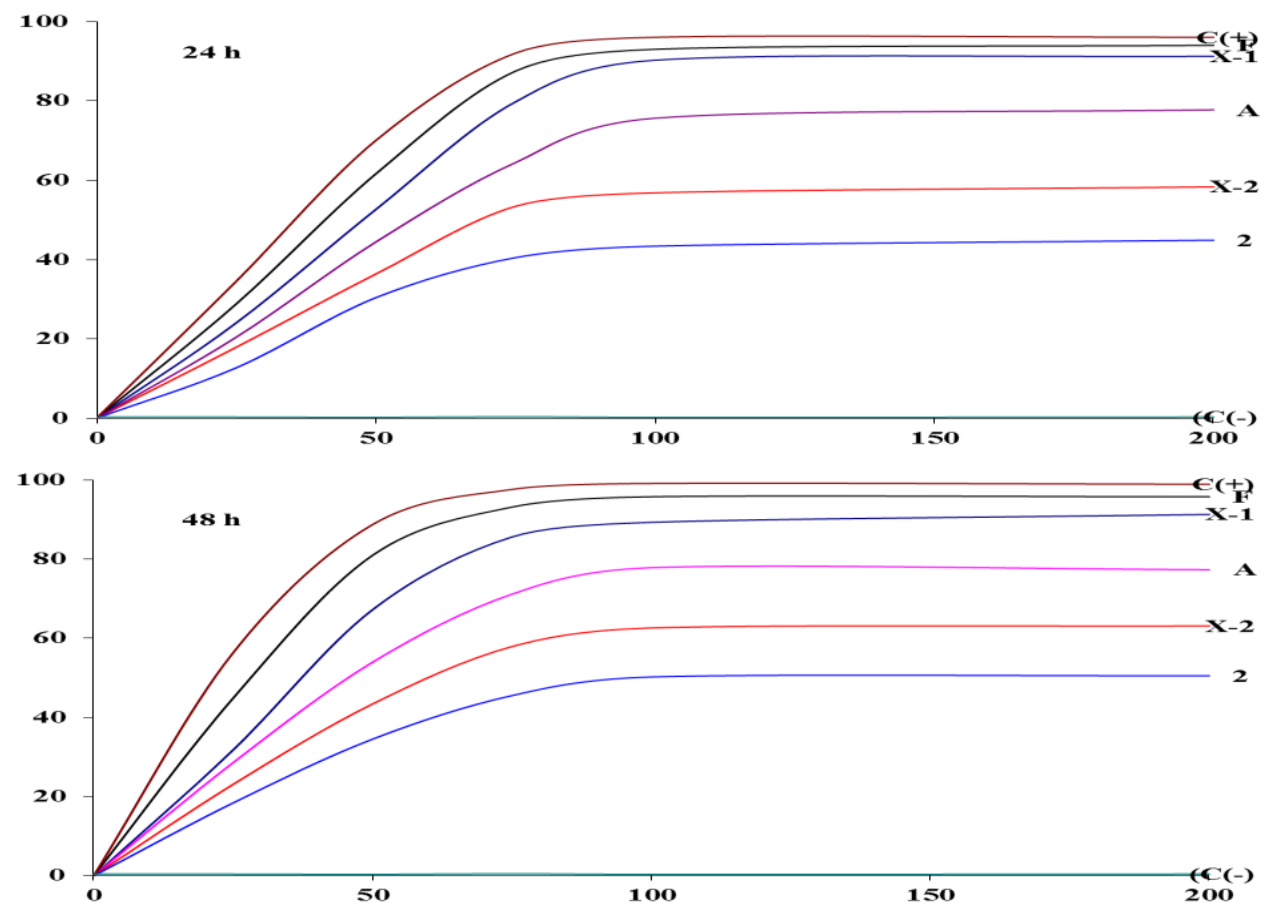

Figure 2: Mortalities of An. gambiae s.s. larvae caused by fractions isolated from EOs of T. minuta, $O$. kilimandscharicum and A. afra after 24- and 48- hours of exposure under SFCs

Key:

$\mathrm{C}(+)$ - Positive Control (containing $1 \mathrm{~g} / \mathrm{L} \mathrm{Bi}-\mathrm{Larv}^{\mathrm{TM}} 25 \mathrm{WP}$ )

$\mathrm{C}(-)$ - Negative control (containing $4 \mathrm{~mL} / \mathrm{L}$ acetone)

F-Fraction F (containing 31.5\% $\beta$-Caryophyllene)

X-1- Fraction X-1 (containing 37.4\% $\beta$-thujone)

A - Fraction A (containing 29.3\% $\alpha$-Cubebene)

X- 2 - Fraction X-2 (containing $40.8 \%$ Ethyl-2-octynoate)

2 - Fraction 2 (containing $56.3 \% \beta$-ocimene)

A total of seven compounds, constituting about $96.62 \%$ of the compounds present in Fraction 2, were identified from the GC-MS analysis (Table 3). The major compounds identified in the fraction were $\beta$-ocimene (56.29\%), 3methyl-2-hexanol (17.87\%), and 4-Octen-3-one (8.39\%).

Table 3: Compounds identified in Fraction 2, obtained from EO of T. minuta

\begin{tabular}{|r|l|r|r|}
\hline RT (min) & Compound name & $\begin{array}{l}\text { Concentration } \\
(\mathrm{ng} / \mathrm{mg})\end{array}$ & \multicolumn{1}{l|}{$\begin{array}{l}\text { Percentage } \\
\text { composition }\end{array}$} \\
\hline 4.74 & Methyl Isobutyl Ketone & $2.76 \pm 0.01$ & 1.71749 \\
\hline 8.24 & 3-methyl-2-hexanol & $29.85 \pm 1.02$ & 17.87425 \\
\hline 10.07 & 4-Octen-3-one & $13.49 \pm 0.01$ & 8.39452 \\
\hline 12.52 & $\beta$-ocimene & $90.46 \pm 1.01$ & 56.29123 \\
\hline 16.50 & 1,2-dihydro-1,4,6-trimethyl-naphthalene & $6.44 \pm 0.52$ & 4.00747 \\
\hline 20.94 & $\alpha$-Bisabolol & $6.59 \pm 0.27$ & 4.10081 \\
\hline
\end{tabular}

Ten compounds, constituting about $95.29 \%$ of the compounds present in Fraction A, were identified from the GCMS analysis (Table 4). The major compounds identified in the fraction were $\alpha$-cubebene (29.40\%), 5,8-dimethylquinoline (27.02\%), and longifolene (10.04\%).

Table 4: Compounds identified in Fraction A, obtained from EO of $O$. kilimanscharicum \begin{tabular}{|l|l|l}
$\mathrm{RT}(\mathrm{min})$ & Compound name & Concentration
\end{tabular} 


\begin{tabular}{|r|l|r|r|}
\hline & & $(\mathrm{ng} / \mathrm{mg})$ & \multicolumn{1}{|c|}{ composition } \\
\hline 11.49 & $\alpha$-Terpinene & $13.44 \pm 0.21$ & 2.64566 \\
\hline 12.29 & $\gamma$-Terpinene & $1.67 \pm 0.03$ & 0.32874 \\
\hline 16.77 & Longifolene & $50.99 \pm 1.03$ & 10.03740 \\
\hline 17.15 & $\alpha$-Cubebene & $149.24 \pm 2.30$ & 29.39961 \\
\hline 17.58 & 8,9 -dehydro-cycloisolongifolene & $36.46 \pm 0.56$ & 7.17717 \\
\hline 19.32 & 5,8 -dimethyl-quinoline & $137.35 \pm 1.27$ & 27.01575 \\
\hline 20.13 & Humulene II epoxide & $39.59 \pm 1.87$ & 7.79331 \\
\hline 20.83 & Isoaromadendrene epoxide & $42.51 \pm 2.31$ & 8.36811 \\
\hline 21.23 & Isolongifolene, 9,10 -dehydro- & $11.65 \pm 0.21$ & 2.29331 \\
\hline 23.63 & Guaiol & $1.00 \pm 0.01$ & 0.19685 \\
\hline
\end{tabular}

A total of eight compounds, constituting about $96.54 \%$ of the compounds present in Fraction F, were identified from the GC-MS analysis (Table 5). Major compounds identified in Fraction F were $\beta$-caryophyllene (31.45\%), $\beta$-thujone (18.37\%), caryophyllene oxide (11.73\%), $\alpha$-terpineol (11.52\%), and Terpinen-4-ol (11.41\%).

Table 5: Compounds identified in Fraction F, obtained from EO of $O$. kilimandscharicum

\begin{tabular}{|r|l|r|r|}
\hline RT (min) & Compound name & $\begin{array}{r}\text { Concentration } \\
(\mathrm{ng} / \mathrm{mg})\end{array}$ & $\begin{array}{r}\text { Percentage } \\
\text { composition }\end{array}$ \\
\hline 11.75 & Eucalyptol & $46.92 \pm .14$ & 3.60923 \\
\hline 12.78 & $\alpha$-terpineol & $149.74 \pm 3.47$ & 11.51846 \\
\hline 12.99 & Linalool & $102.32 \pm 2.68$ & 7.87077 \\
\hline 13.28 & $\beta$-thujone & $238.76 \pm 2.31$ & 18.36615 \\
\hline 14.29 & Terpinen-4-ol & $148.35 \pm 2.01$ & 11.41154 \\
\hline 16.91 & 3-Allyl-6-methoxyphenol & $7.96 \pm 0.21$ & 0.61230 \\
\hline 17.76 & $\beta$-Caryophyllene & $409.36 \pm 1.57$ & 31.48923 \\
\hline 19.84 & Caryophyllene oxide & $152.46 \pm 0.87$ & 11.72769 \\
\hline
\end{tabular}

A total of seven compounds, constituting about $97.72 \%$ of the compounds present in Fraction X-1, were identified from the GC-MS analysis (Table 6). The major compounds identified in the fraction were $\beta$-thujone (37.41\%), Terpinen-4-ol (21.92\%), Thujol (13.34\%), and $\alpha$-terpineol (11.55\%).

Table 6: Compounds identified in Fraction X-1, obtained from EO of A. afra

\begin{tabular}{|r|l|r|r|}
\hline RT (min) & Compound Name & $\begin{array}{l}\text { Concentration } \\
(\mathrm{ng} / \mathrm{mg})\end{array}$ & \multicolumn{1}{l|}{$\begin{array}{l}\text { Percentage } \\
\text { composition }\end{array}$} \\
\hline 11.75 & Eucalyptol & $59.27 \pm 3.21$ & 2.24508 \\
\hline 12.43 & $($ Z)- $\beta$-terpineol & $92.98 \pm 3.57$ & 3.52197 \\
& & & 21.92197 \\
\hline 13.10 & Terpinen-4-ol & $578.74 \pm 4.68$ & 11.55303 \\
\hline 14.20 & $\alpha$-terpineol & $305.28 \pm 2.37$ & 37.41174 \\
\hline 14.31 & $\beta$-thujone & $987.67 \pm 3.78$ & 13.33909 \\
\hline 14.40 & Thujol & $352.68 \pm 1.34$ & 7.62462 \\
\hline 14.53 & Cis-p-menth-2-en-7-ol & $201.29 \pm 5.63$ & \\
\hline
\end{tabular}

Eight compounds, constituting about $96.80 \%$ of the compounds present in Fraction X-2, were identified from the GC-MS analysis (Table 7). The major compounds identified in the fraction were Ethyl-2-octynoate (40.81\%), 4propyl-1,6-heptadien-4-ol (26.17\%), and 2-Allyl-4-methylphenol (14.62\%). 
Table 7: Compounds identified in Fraction X-2, obtained from EO of A. afra

\begin{tabular}{|c|c|c|c|}
\hline RT (Min) & Compound Name & $\begin{array}{l}\text { Concentration } \\
(\mathrm{ng} / \mathrm{mg})\end{array}$ & $\begin{array}{l}\text { Percentage } \\
\text { composition }\end{array}$ \\
\hline 9.08 & 2-ethyl-hexanal & $6.34 \pm 0.52$ & 1.19397 \\
\hline 10.07 & 2-Pyrazoline, 1-isobutyl-3-methyl- & $3.46 \pm 2.15$ & 0.65160 \\
\hline 14.10 & (E)-2,3-Epoxydecane & $28.84 \pm 3.28$ & 5.43126 \\
\hline 14.66 & 2,3,4-trimethyl-2-Cyclopenten-1-one & $34.81 \pm 3.58$ & 6.55556 \\
\hline 17.46 & 2-Allyl-4-methylphenol & $75.73 \pm 0.54$ & 14.61770 \\
\hline 18.33 & 4-propyl-1,6-heptadien-4-ol & $138.96 \pm 3.85$ & 26.16949 \\
\hline 18.47 & Ethyl-2-octynoate & $216.68 \pm 3.57$ & 40.80603 \\
\hline 20.96 & Spiro[5.6]dodecane & $9.14 \pm 3.52$ & 1.72128 \\
\hline
\end{tabular}

\section{Discussion:-}

The fractions with remarkably high larvicidal activity against third instar larvae of An. gambiae s.s. were obtained from the non-polar and slightly polar eluates of the respective EOs used in this study. This was in agreement with Pineda-Cortel, et al., (2019), who reported that the extraction of active biochemical compounds from plants depended on the polarity of the solvents used in extraction. Ghosh et al. (2012), also reported that different solvent types significantly affect the potency of extracted phytochemicals, and that moderately polar solvents such as ethyl acetate provided good bioassay results. Furthermore, AhbiRami et al. (2014), stated that insecticidal compounds are contained in various proportions in different polarity fractions, being higher in lower polarities. The findings of this study, therefore, were in conformity with those reported by Ghosh, et al., (2012), AhbiRami, et al., (2014), and Pineda-Cortel, et al., (2019), because the five most potent fractions in this study were isolated in the non-polar and slightly polar eluates during column chromatography of $T$. minuta , O. kilimandscharicum and A. afra EOs, respectively. However, their activities varied with plant species with the two most efficacious fractions being fractions F and X-1 isolated from EOs of $O$. kilimandscharicum and A. afra, respectively.

While the most potent fractions from T. minuta (Fraction 2) and A. afra (Fraction X-1) were obtained from the nonpolar eluates, that of $O$. kilimandscharicum (Fraction F) was obtained from the slightly polar eluates. This implies that the most active compounds in the three plants had different molecular weights and solubilities, hence their elution at different polarities. In a previous study and while testing the biological activity of crude EOs of $O$. kilimandscharicum and A. afra against Culex quinquefasciatus, Runyoro, et al., (2010) reported that the former had higher bioactivity than the latter with $323.6 \mathrm{ppm}$ and $457.1 \mathrm{ppm}$ of the EOs required to induce $50 \%$ mortality of $C x$. quinquefasciatus larvae. In the same study, it was also reported that $1000 \mu \mathrm{g}$ of crude EO of $O$. kilimandscharicum exhibited an inhibition zone of $21.0 \mathrm{~mm}$ against Candida albicans while a similar quantity of T. minuta had a 12.5 mm inhibition zone.

Even though the $\mathrm{LC}_{50}$ values reported in current study show great disparity when compared with those reported by Runyoro, et al., (2010), the findings of both studies are in agreement that $O$. kilimandscharicum is a better source of bioactive compounds than A. afra and T. minuta. According to Pineda-Cortel, et al. (2019), variations in insecticidal activities of plant extracts could be attributed to several factors such as plant species, part of the plant used, age of the plant, and the targeted vector species. The great disparity is indicative of a higher concentration of active compounds in the fractions used in this study than in the crude EOs in which they could have been masked by the less active or completely inactive constituents.

The mortality trends observed in the semi-field experiments were similar to those in laboratory assays, being dosage- and exposure time-dependent. However, actual mortality rates were comparatively higher under semi-field conditions than those recorded under laboratory conditions in similar treatment concentrations of some fractions. This conformed to the findings of Kweka, et al., (2011) and Nyamoita, et al., (2013) with both groups attributing the higher larval mortalities under SFCs to contributions of other variables in the surroundings, a normal adaptive biodiversity output. According to Kweka, et al. (2011), the exposure of plant extracts to sunlight triggers degradation of phytochemicals to their secondary metabolites, to which higher larval mortalities under SFCs than laboratory conditions had been attributed. Besides, since the larvae used in this study were laboratory bred as opposed to wild forms, their mere introduction into a new set of habitat conditions could on its own make them more susceptible to the treatments to which they were subjected compared to their usual laboratory conditions. 
The results of the current study, however, differed from those reported by Karunamoorthi, et al., (2014), who while testing the larvicidal efficacy of EOs from Juniperus procera against An. arabiensis, found larval mortality under laboratory conditions to have been significantly higher with $\mathrm{LC}_{50}$ and $\mathrm{LC}_{90}$ values of 14.42 and $24.65 \mathrm{mg} / \mathrm{L}$, which were $10 \mathrm{mg} / \mathrm{L}$ lower than concentrations recorded under SFCs $\left(\mathrm{LC}_{50}\right.$ and $\mathrm{LC}_{90}$ values 24.518 and $34.212 \mathrm{mg} / \mathrm{L}$ ), respectively. However, while laboratory reared larvae were used under both laboratory and SFCs in this study, Karunamoorthi, et al., (2014) had used laboratory reared and wild larvae for laboratory and semi-field experiments, respectively. This could be the reason for disagreement in the findings between their study and the current one. Nevertheless, the authors had still found laboratory reared anopheline larvae to have been more susceptible than wild collected ones. On the other hand, the findings of this study were in line with those of Nyamoita, et al., (2013), who while testing the activity of Vitex payos against laboratory reared An. gambiae s.s larvae, found those under SFCs to have been more susceptible than the ones under laboratory conditions. In conclusion, the development of suitable formulations of biocides from EOs of T. minuta, O. kilimascharicum, and A. afra is feasible with fractions $\mathrm{F}$ from $O$. kilimadscharicum and X-1 from A. afra being more promising.

\section{Acknowledgements:-}

The authors acknowledge the National Commission for Science and Technology (NACOSTI) currently National Research Fund (NRF) for funding the research.

\section{Conflict of interest}

The authors declare no conflict of interest.

\section{Author's contribution}

The $1^{\text {st }}$ author participated in data collection and processing, and writing the manuscript, while the $2^{\text {nd }}$ and $3^{\text {rd }}$ authors participated in development of the research question and design, and correcting the manuscript.

\section{References:-}

1. Afolabi, O.J., Simon-Oke, I.A., Elufisan, O.O. and Oniya, M.O. (2018). Adulticidal and Repellent Activities of some Botanicals against Malaria Mosquito: Anopheles gambiae (Diptera: Culicidae). Beni-Suef University Journal of Basic and Applied Sciences. 7: 135-138

2. Agresti, A. (1990). Categorical Data Analysis. Wiley, New York.

3. AhbiRami, R., Zuharah, W.F., Thiagaletchumi, M., Subramaniam, S. and Sundarasekar, J. (2014). Larvicidal Efficacy of Different Plant Parts of Railway Creeper, Ipomoea cairica Extract against Dengue Vector Mosquitoes, Aedes albopictus (Diptera: Culicidae) and Aedes aegypti (Diptera: Culicidae). Journal of Insect Science. 14(180): 1-6. DOI: 10.1093/jisesa/ieu042

4. Amerasan, D., Murugan, K., Kovendan, K., Kumar, P.M., Panneersevam, C., Subramaniam, J., William, S.J. and Hwaang, J. (2012). Adulticidal and Repellent Properties of Cassia tora Linn. (Family: Caesalpinaceae) against Culex quinquefasciatus, Aedes aegypti, and Anopheles stephensi. Parasitology Research: DOI 10.1007/s00436-01203042-3

5. Baser, K.H.C and Buchbauer, G. Eds. (2010). Handbook of Essential Oils: Science, Technology, and Applications. CRC Press-Taylor and Francis: New York.

6. Bekele, D. (2018). Review on Insecticidal and Repellent activity of Plant Products for Malaria Mosquito Control. Biomedical Research and Reviews, 2(2): 1-7

7. Camara, S., Koffi, A.A., Alou, L.P.A., Kabran, J.P.K., Koné, A., Koffi, M.F., N'Guessan, R. and Pennetier, C. (2018). Mapping Insecticide Resistance in Anopheles gambiae s.l. from Côte d'Ivoire. Parasites and Vectors. 11(19): DOI: 10.1186/s13071-017-2546-1

8. Cuthbert, R.N., Ortiz-Perea, N., Dick, J.T.A. and Callaghan, A. (2019). Elusive Enemies: Consumptive and Ovipositional Effects on Mosquitoes by Predatory Midge Larvae are Enhanced in Dyed Environments. Biological Control. 132: 116-121.

9. Finney, D. J., ed. (1952). Probit Analysis. Cambridge, England, Cambridge University Press.

10. Ghosh, A., Chowdhury, N. and Chandra, G. (2012). Plant extracts as Potential Mosquito Larvicides. Indian Journal of Medical Research, 135: 581-598

11. Hamilton, W.L., Amato, R., Pluijm, R.W., Jacob, C.G., Quang, H.H., Thuy-Nhein, N.T., et al. (2019). Evolution and Expansion of Multi-Drug Resistant Malaria in Southeast Asia: a Genomic Epidemiology Study. Lancet infectious Diseases. DOI: 10.1016/S1473-3099(19)30392-5 
12. Karunamoorthi, K., Girmay, A. and Fekadu, S. (2014). Larvicidal Efficacy of Ethiopian Ethnomedicinal Plant, Juniperus procera Essential Oil against Afrotropical Malaria Vector Anopheles arabiensis (Diptera: Culicidae). Asian Pacific Journal of Tropical Biomedicine. 4 (1): s99-s106

13. Kisinza, W.N., Nkya, T.E., Kabula, B., Overgaard, H.J., Massue, D.J., Mageni, Z., Greer, G., Kaspar, N., Mohamed, M., Reithinger, R., Moore, S., Lorenz, L.M. and Magesa, S. (2017). Multiple Insecticide Resistance in Anopheles gambiae from Tanzania: a Major Concern for Vector Control. Malaria Journal, 16(439): 1-9. DOI: 10.1186/s12936-017-2087-2

14. Kweka, E. J., Nyindo, M., Mosha, F. and Silva, A.G. (2011). Insecticidal activity of the Essential Oil from Fruits and Seeds of Schinus terebinthifolia Raddi against African Malaria Vectors. Parasites and Vectors, 4 (129): 1-11.

15. Lynd, A., Oruni, A., van`t Hof, A.E., Morgan, J.C., Naego, L.B., Pipini, D., O’Kines, K.A., Bobanga, T.L., Donnelly, M.J. and Weetman, D. (2018). Insecticide Resistance in Anopheles gambiae from the Northern Democratic Republic of Congo, with Extreme Knockdown Resistance (kdr) Mutation Frequencies Revealed by a new Diagnostic Assay. Malaria Journal, 17(412): 1-7. DOI: 10.1186/s12936-018-2561-5

16. Nyamoita, M.G., Mbwambo, Z.H., Ochola, B.J., Innocent, E., Lwande, W. and Hassanali, A. (2013). Chemical Composition and Evaluation of Mosquito Larvicidal Activity of Vitex payos Extracts against Anopheles gambiae Giles s.s. Larvae. Spatula DD. 3(3): 113-120

17. Okia, M., Hoel, D.F., Kirunda, J., Rwakimari, J.B., Mpeka, B., Ambayo, D., Price, A., Oguttu, D.W., Okul, A.P. and Govere, J. (2018). Insecticide Resistance of the Malaria Mosquitoes: Anopheles gambiae and Anopheles funestus in Eastern and Northern Uganda. Malaria Journal. 17(157): 1-11 DOI: 10.1186/s12936018-2293-6

18. Pavela, R., Maggi, F., Iannarelli, R. and Benelli, G. (2019). Plant Extracts for Developing Mosquito Larvicides: from Laboratory to the Field, with Insights on the Mode of Action. Acta Tropica, 193: 236-271

19. Pavia, D. L., Lampman, G. M. and Kriz, Jr. G. S. (1982). Introduction to Organic Laboratory Techniques: a Contemporary Approach, $2^{\text {nd }}$ edition. Philadelphia: CBS College Publishing.

20. Pineda-Cortel, M., Cabantog, R.J.R., Caasi, P.M., Ching, C.A.D., Perz, J.B.S., Godisan, P.G.M., Latorre, C.M.G., Lucero, D.R. and Salonga, R.B. (2019). Larvicidal and Ovicidal Activities of Artocarpus blancoi Extracts against Aedes aegypti. Pharmaceutical Biology 57(1): 120-124

21. Runyoro, D.K.B., Ngassapa, O., Kachali, L., Obare, V. and Lyamuya, E.F. (2010). Biological Activities of Essential Oils from Plants Growing in Tanzania. East and Central African Journal of Pharmaceutical Sciences. 13: 85-91

22. Sanei-Dehkordi, A., Vatandoost, H., Abaei, M. R., Davari, B. and Sedaghat, M. M. (2016). Chemical Composition and Larvicidal Activity of Bunium persicum Essential Oil Against Two Important Mosquitoes Vectors. Journal of Essential Oil-Bearing Plants, 19:2, 349-357, DOI: 10.1080/0972060X.2015.1137240

23. Uragaya, S., Verma, V., Natarajan, E., Velamuri, P.S. and Kamaraju, R. (2015). Adulticidal and Larvicidal Efficacy of three Neonicotinoids against Insecticide Susceptible and Resistant Mosquito Strains. Indian Journal of Medical Research. 142: 64-70 DOI: 10.4103/0971-5916.176624

24. WHO, (2005). Guidelines for Laboratory and Field Testing of Mosquito Larvicides: World Health Organization Communicable Disease Control, Prevention and Eradication, WHO Pesticide Evaluation Scheme. WHO/CDS/WHOPES/GCDPP/2005.13.

25. WHO, (2013). Malaria Entomology and Vector Control: Guide for Participants. Malta: World Health Organization.

26. WHO, (2018). World Malaria Report 2018. Luxembourg: World Health Organization.

27. Zoh, D.D., Alou, L.P.A., Toure, M., Penntier, C., Camara, S., Traore, D.F., Koffi, A.A., Adja, A.M., Yapi, A. and Chandre, F. (2018). The Current Insecticide Resistance Status of Anopheles gambiae s.l. (Culicidae) in Rural and Urban Areas of Bouaké Côte d'Ivore. Parasites and Vectors. 11(118): 1-11. DOI: 10.1186/s13071018-2702-2. 